\title{
PENGARUH LINGKUNGAN FISIK TERHADAP IMPRESI KONSUMEN PADA KEDAI KOPI KEKINIAN DI SURABAYA
}

\author{
Hansen Jan Soepriyanto ${ }^{1}$, Michelle Christiana ${ }^{2}$, Agung Harianto ${ }^{3 *}$ \\ 1,2,3 Program Manajemen Perhotelan, Program Studi Manajemen, Fakultas Bisnis dan Ekonomi, \\ Universitas Kristen Petra, Jl. Siwalankerto 121-131, Surabaya, Indonesia \\ Email: ${ }^{1}$ hansen.jan23@gmail.com; ${ }^{2}$ mich.christiana@yahoo.com; ${ }^{3}$ agung.harianto@ petra.ac.id \\ *Penulis Korespondensi
}

\begin{abstract}
Abstrak
Penelitian ini bertujuan untuk mengetahui pengaruh lingkungan fisik yang terdiri dari ambience, layout dan facility aesthetic terhadap impresi konsumen pada kedai kopi kekinian yang ada di Surabaya. Metode yang di gunakan dalam penelitian ini menggunakan analisa regresi linier berganda dengan total responden sebanyak 149. Hasil dari penelitian menunjukan bahwa terdapat hubungan yang positif dan signifikan pada lingkungan fisik terhadap impresinya pada konsumen kedai kopi di Surabaya.
\end{abstract}

Kata kunci: Ambience; Layout; Facility Aesthetic; Impresi Konsumen; Kedai Kopi Kekinian.

\begin{abstract}
This study is done to reveal the influence of physical environment which are ambience, layout and facility aesthetic on consumer's impression towards trendy coffee shop/ fourth wave coffee shops in Surabaya. The method used in this study is multiple linear regression with a total of 149 respondents. The result shows that physical environment has a significant and positive influence towards consumers impression towards trendy coffee shops/4th wave coffee shop in Surabaya.
\end{abstract}

Keywords: Ambience; Layout, Facility Aestheti; Consumer Impression; Trendy Coffee Shop.

\section{PENDAHULUAN}

Perkembangan kopi di Indonesia dimulai pada tahun 1696 melalui campur tangan Pemerintah Belanda dengan membawa kopi dari Malabar ke Indonesia kemudian didistribusikan ke Batavia, Cirebon, kawasan Priangan serta wilayah pesisir utara Pulau Jawa dan berhasil dibudidayakan pada tahun 1714-1715 (Risnandar, 2019). Perkembangan kopi di Indonesia melaju dengan pesat hingga menurut Statista, saat ini Indonesia dikenal sebagai salah satu negara penghasil kopi terbesar di dunia setelah Brazil, Vietnam, dan Kolombia. Berdasarkan dari data oleh International Coffee Organization konsumsi kopi di Indonesia kian meningkat tiap tahunnya. Hal ini menunjukkan bahwa ada tren positif dalam perkembangan maupun pertumbuhan industri kopi nasional yang berdampak pada meningkatnya konsumsi kopi nasional (Alfirahmi, 2019).

Berdasarkan data yang diperoleh dari Toffin, bisnis kedai kopi di Indonesia terbagi menjadi 4 gelombang, sebelum munculnya kedai kopi di Indonesia sebagian besar masyarakat Indonesia menikmati kopi instan dalam kemasan seperti Kapal Api, Kopi ABC, Torabika, dan Nescafe, hingga pada akhirnya muncul kedai kopi modern yaitu Dunkin 'Donuts (1985), Olala (1990) dan Excelso (1991) sebagai gelombang pertama bisnis kedai kopi di Indonesia. Gelombang kedua dimulai pada tahun 2000 yang ditandai dengan munculnya brand kopi internasional yang berasal dari Amerika Serikat seperti Starbucks, Coffee Bean, dan Segafredo.

Gelombang ketiga dimulai pada tahun 2010, ditandai dengan hadirnya artisan coffee shop seperti Tanamera yang menyajikan art coffee. Hadirnya art coffee menimbulkan rasa antusias konsumen kedai kopi terhadap proses pembuatan kopi dari biji menjadi segelas kopi. Kedai kopi ready to go seperti Kopi Kenangan, Kopi Janji Jiwa, Fore, dan Tuku mulai muncul pada tahun 2016 sebagai pelopor gelombang keempat dari bisnis kopi di Indonesia. Gelombang keempat ini menyebabkan bisnis kedai kopi di Indonesia berkembang secara pesat yang dapat dilihat dari riset independen Toffin dan Group Majalah SWA pada Agustus 2019, kedai kopi di Indonesia berjumlah sekitar 2950 kedai, angka tersebut meningkat 3x lipat 
dari tahun 2016 yang hanya berjumlah hanya sekitar 1000 kedai (Widiati, 2020). Pesatnya perkembangan kopi gelombang keempat di Indonesia dapat dilihat berdasarkan penghargaan MURI yang berhasil diraih oleh Kopi Janji Jiwa. Janji Jiwa berhasil memperluas gerainya hingga 719 gerai yang tersebar di Indonesia dalam kurun waktu satu tahun, menjadikannya kedai kopi dengan pertumbuhan tercepat dalam satu tahun.

Berdasarkan data yang diperoleh dari Toffin selaku platform bisnis kopi ternama di Indonesia, interior kedai kopi merupakan salah satu formula agar bisnis kedai kopi dapat bertahan dimana interior pada suatu kedai kopi akan berpengaruh kepada ambience gerai yang bisa menjadi magnet bagi pengunjung sedangkan impresi seseorang terhadap suatu hotel atau instansi didasari dari tinjauannya pada lingkungan sekitarnya (Jani \& Han, 2014) maka dapat disimpulkan bahwa lingkungan fisik yang baik akan membentuk impresi yang baik terhadap kedai kopi terkait. Impresi yang baik pada umumnya akan menciptakan preferensi konsumen dalam memilih kedai kopi kekinian.

Berdasarkan fenomena ini penulis ingin mengetahui apa yang menjadi preferensi konsumen dalam memilih kedai kopi dari sisi lingkungan fisik. Menurut penelitian Muhammad \& Lee (2015), lingkungan fisik berperan penting pada cafe dalam menumbuhkan impresi dan memanipulasi perilaku konsumen. Lingkungan fisik adalah salah satu faktor yang dilakukan pada pelanggan untuk mendapatkan approach behaviour. Approach behaviour adalah keinginan pelanggan untuk mendatangi dan menetap pada suatu restoran dan dianggap sebagai respon yang positif (Ryu \& Jang, 2007). Berdasarkan penelitian oleh Muhammad \& Lee (2015) impresi berperan sebagai mediasi untuk mempengaruhi preferensi pelanggan dalam memilih coffee shop, dimana impresi dipengaruhi oleh lingkungan fisik yaitu ambience, atmosphere dan layout (Bitner, 1992; Ryu \& Jang, 2007).

\section{TINJAUAN PUSTAKA}

\section{Lingkungan Fisik}

Lingkungan fisik didefinisikan sebagai karakteristik objektif, "the man-made, physical surroundings as opposed to the natural or social environment", yang berarti lingkungan sekitar yang dibuat oleh manusia sebagai lawan dari alam atau lingkungan sosial (Bitner, 1992, p. 58). Lingkungan fisik diciptakan untuk mendukung layanan yang diberikan oleh suatu perusahaan (Bitner, 1992). Konsumen memandang lingkungan fisik sebagai salah satu dimensi yang mempengaruhi keseluruhan impresi, secara independen maupun dengan interaksinya dengan variabel lain, lingkungan fisik juga menjadi karakteristik suatu perusahaan dan dapat membantu konsumen untuk dapat membedakan antara satu restoran dengan yang lain (Yazid, 2001; Countryman \& Jang, 2006). Wall dan Berry yang dikutip dalam Arifin et al (2010) menyatakan dalam penelitian yang dilakukan, bahwa meskipun kualitas makanan adalah dasar, suasana (ambient) dan kinerja layanan sangat mempengaruhi evaluasi konsumen terhadap suatu restoran. Lingkungan fisik perlu untuk dapat memuaskan panca indera yang meliputi penglihatan, penciuman, pendengaran, dan sentuhan karena konsumen dengan mudah mengingat lingkungan sekitar yang berdampak pada dirinya (Muhammad \& Lee, 2015; Jani \& Han, 2014).

Ambience didefinisikan sebagai sesuatu yang mengelilingi atau mencakup karena berkaitan dengan lingkungan (Blanchard, 2005). Menurut Ryu \& Jang (2007) dan Khan (2006) mendefinisikan ambience sebagai kondisi suasana yang mengacu pada latar belakang yang tidak berwujud dan cenderung mempengaruhi panca indera nonvisual. Ambience mencakup elemen yang dianggap sebagai karakteristik latar belakang lingkungan fisik, contohnya adalah aroma yang menyenangkan, musik yang menyenangkan, suhu yang nyaman, tingkat kebisingan yang rendah dan pencahayaan yang memadai (Arifin et al., 2010). Ambience mengelilingi kehidupan sehari-hari, contohnya seperti background music yang memenuhi restoran, mall, bahkan di lift (Blanchard, 2005). Menurut penelitian Griffitt yang dikutip oleh Bitner (1992) saat seseorang merasa tidak nyaman akibat ambience yang ada maka respon juga tidak baik, respon terhadap orang lain juga tidak akan baik.

Layout mengacu pada bagaimana mesin, peralatan, dan perabotan ditata, ukuran dan bentuk item tersebut, dan hubungan spasial diantaranya (Bitner, 1992). Menurut Wakefield \& Blodgett (1994) layout mengacu pada cara-cara di mana meja kursi, lorong dan jalan setapak, jalur layanan makanan, toilet, dan pintu masuk dan keluar dirancang dan diatur dalam pengaturan layanan waktu luang. Salah satu kesalahan terbesar layout pada lobby hotel adalah ketika letak resepsionis tidak bisa langsung terlihat pada saat tamu datang dan ketidaklancaran arus pada resepsionis, layout harus bisa meminimalisasi kesesakan untuk dapat membentuk impresi yang baik pada konsumen (Countryman \& Jang, 2006). Layout atau tata letak 
merupakan salah satu atribut yang memiliki pengaruh pada impresi konsumen, kesenangan, dan kemauan untuk kembali ke restoran tersebut, selain itu restoran juga harus memastikan bahwa tata letak ruang sesuai dan nyaman untuk konsumen (Ryu \& Jang, 2008). Layout yang efektif adalah yang memberikan kemudahan pada akses masuk dan keluar, Ryu \& Jang (2008) juga mengatakan bahwa impresi pengunjung hotel bergantung salah satunya pada layout. Efisiensi layout/tata letak juga sangat penting bagi konsumen karena hal tersebut juga menyangkut ruang gerak konsumen (Bitner, 1992)

Estetika fasilitas didefinisikan sebagai nilai estetika atau keindahan pada fasilitas yang terkait atau dalam penelitian ini nilai estetika atau keindahan dari lingkungan fisik pada kedai kopi kekinian, sebagai fungsi desain arsitektur, bersama dengan desain interior dan dekorasi, yang berkontribusi pada servicescape dan pada daya tarik restoran (Ryu \& Jang, 2007, 2008). Daya tarik estetika mengacu pada faktor-faktor seperti lingkungan eksternal sekitar, desain arsitektur, papan nama, dan elemen fisik lainnya yang dilihat oleh pelanggan (dan mengevaluasi kualitas estetika) pada lingkungan fisik sebuah fasilitas dan ini adalah hal yang penting karena dapat mempengaruhi keseluruhan suasana pada sebuah fasilitas (Wakefield \& Blodgett, 1994). Unsur estetika fasilitas juga mencakup lukisan / gambar, dekorasi, tanaman / bunga, warna, dan furnitur, yang kesemuanya merupakan elemen estetika yang menciptakan citra atau suasana estetika (Ryu \& Jang, 2008).

Impresi menurut KBBI (kamus besar bahasa indonesia) memiliki arti sebagai berikut, kesan, efek pada indera, efek atau pengaruh sesuatu terhadap pikiran atau perasaan. Impresi dideskripsikan sebagai keyakinan, perilaku, atau citra seorang individu terhadap sebuah subjek, subjek dapat berupa produk, perusahaan, merek ataupun orang. Apakah sebuah kesan itu nyata atau tidak, benar ataupun salah itu bukanlah yang terpenting, yang penting adalah bagaimana kesan membentuk perilaku dan mengarahkan konsumen untuk membuat keputusan berdasarkan impresi tersebut (Durna et al., 2015). Impresi memiliki tujuan untuk mendapatkan respon dari target atau konsumen, yang bisa dimanipulasi dengan informasi atau keadaan tertentu (Tedeschi, 1984). Menurut Stanton et al. (1998) impresi dapat didefinisikan sebagai makna yang dipertalikan berdasarkan pengalaman masa lalu, stimuli (rangsangan) yang diterima melalui kelima indra. Impresi adalah usaha untuk mempengaruhi persepsi seseorang terhadap sesuatu dan impresi bukan tentang mencari persetujuan. Penyedia barang atau jasa harus menyediakan sesuatu sebagai stimuli yang jika ingin menarik perhatian konsumen, respon dari setiap orang terhadap sesuatu akan berbeda-beda, oleh karena itu impresi memiliki sifat yang subjektif. Impresi yang dibentuk oleh seseorang dipengaruhi oleh pikiran dan lingkungan sekitarnya (Setiadi, 2013).

Hipotesis dalam penelitian ini adalah Ambience, Layout, Facility Aesthetic berpengaruh secara signifikan pada impresi konsumen

\section{METODE PENELITIAN}

Jenis penelitian yang digunakan dalam penelitian ini adalah kuantitatif kausal dimana penelitian jenis ini merupakan penelitian dengan menggunakan perhitungan metode statistik (Kuncoro, 2003). Pendekatan kuantitatif berfokus pada keluasan informasi (bukan kedalaman), oleh karenanya output hasil penelitian dapat dianggap mewakili seluruh populasi (Sugiyono, 2004). Teknik yang digunakan untuk mengambil sampel dalam penelitian ini adalah teknik purposive sampling yang termasuk dalam probability sampling. Purposive sampling menurut Sugiyono (2017) adalah teknik penentuan sampel dengan pertimbangan tertentu yang bertujuan agar data yang diperoleh nantinya bisa lebih representatif. Pertimbangan dalam pemilihan sampel adalah sebagai berikut:

1. Responden berusia minimal 17 tahun

2. Konsumen yang secara fisik pernah datang dan berkunjung ke kedai kopi kekinian di Surabaya dalam kurun waktu Juni 2020 - November 2020 (setelah peraturan PSBB dicabut di Surabaya).

\section{HASIL DAN PEMBAHASAN}

Berdasarkan hasil uji validitas yang dilakukan dengan SPSS 26 semua variabel dalam penelitian ini valid. Sedangkan untuk uji reliabelitas menggunakan metode cronbach alpha dimana setiap variabel dalam penelitian ini yaitu ambience (X1), layout (X2), facility aesthetic (X3) serta impresi $(\mathrm{Y})$ mendapatkan nilai lebih dari 0.6 sehingga dapat disimpulkan seluruh variabel dalam penelitian ini reliabel. Begitu juga untuk uji normalitas dan multikolinearitas normal dan tidak terdapat gejala multikolinearitas. 


\section{Hasil Mean dan Standar Deviasi Variabel Lingkungan Fisik}

Tabel 1. Mean dan standart Deviasi Variabel Lingkungan Fisik

\begin{tabular}{|c|c|c|}
\hline Pernyataan & Mean & Sd \\
\hline Ambience (X1) & 4.31 & \\
\hline $\begin{array}{l}\text { Kedai kopi memiliki suhu udara } \\
\text { yang nyaman }\left(23-26^{\circ} \mathrm{C}\right)\end{array}$ & 4.13 & .818 \\
\hline $\begin{array}{l}\text { Kedai kopi memiliki aroma yang } \\
\text { menyenangkan (aroma kopi, } \\
\text { pewangi ruangan) }\end{array}$ & 4.48 & .746 \\
\hline $\begin{array}{l}\text { Pencahayaan pada kedai kopi } \\
\text { menciptakan suasana yang nyaman } \\
\text { (tidak terlalu gelap/terang) }\end{array}$ & 4.50 & 613 \\
\hline $\begin{array}{l}\text { Kedai kopi memberikan latar musik } \\
\text { yang menciptakan suasana } \\
\text { menyenangkan }\end{array}$ & 4.17 & .945 \\
\hline $\begin{array}{l}\text { Secara keseluruhan tingkat } \\
\text { kebisingan pada kedai kopi dapat } \\
\text { diterima (tidak menganggu } \\
\text { komunikasi / obrolan mudah } \\
\text { didengar) }\end{array}$ & 4.31 & .750 \\
\hline Layout (X2) & 4.14 & 2.16 \\
\hline $\begin{array}{l}\text { Penataan tempat duduk pada kedai } \\
\text { kopi memberi saya cukup ruang } \\
\text { (jarak antar meja tidak terlalu } \\
\text { sempit) }\end{array}$ & 4.20 & .813 \\
\hline $\begin{array}{l}\text { Tata letak perabotan pada kedai kopi } \\
\text { memudahkan saya untuk berpindah- } \\
\text { pindah (tidak mengganggu ruang } \\
\text { gerak) }\end{array}$ & 4.24 & .729 \\
\hline $\begin{array}{l}\text { Kapasitas tempat duduk pada kedai } \\
\text { kopi mengakomodasi jumlah } \\
\text { konsumen yang datang }\end{array}$ & 4.00 & 1.03 \\
\hline Facility Aesthetic (X3) & 4.17 & \\
\hline $\begin{array}{l}\text { Lukisan/gambar yang ada pada } \\
\text { kedai kopi menarik secara visual }\end{array}$ & 3.93 & .932 \\
\hline $\begin{array}{l}\text { Dekorasi pada dinding kedai kopi } \\
\text { menarik secara visual }\end{array}$ & 4.18 & .735 \\
\hline $\begin{array}{l}\text { Tanaman/bunga membuat suasana } \\
\text { hati saya lebih baik }\end{array}$ & 4.02 & .904 \\
\hline $\begin{array}{l}\text { Warna yang digunakan menciptakan } \\
\text { suasana yang hangat (warna } \\
\text { cenderung ke warna coklat/krem } \\
\text { dan memberikan kesan yang } \\
\text { menarik secara visual) }\end{array}$ & 4.44 & .675 \\
\hline Furnitur di kedai kopi berkualitas & 4.15 & .793 \\
\hline $\begin{array}{l}\text { Furnitur di kedai kopi mendukung } \\
\text { kenyaman }\end{array}$ & 4.31 & .742 \\
\hline
\end{tabular}

Dari table di atas dapat di lihat bawah untuk nilai mean dan standart deviasi variable fisik memiliki nilai yang menyatakan setuju dan nilai standart deviasi memiliki nilai yang mampu untuk mewakili seluruh populasi.
Hasil Mean dan Standar Deviasi Variabel Impresi

Tabel 2. Mean dan Standart Ceviasi Variabel Impresi

\begin{tabular}{lcc}
\hline Impresi (Y) & 4.43 & \\
$\begin{array}{l}\text { Kedai kopi memiliki reputasi } \\
\text { yang baik }\end{array}$ & 4.46 & .656 \\
$\begin{array}{l}\text { Penampilan kedai kopi mudah } \\
\text { diingat }\end{array}$ & 4.48 & .735 \\
$\begin{array}{l}\text { Lingkungan fisik (penampilan, } \\
\text { suasana, dan layout) kedai kopi } \\
\text { mengundang saya untuk }\end{array}$ & 4.37 & .735 \\
berkunjung & & \\
\hline
\end{tabular}

Dari table di atas dapat di lihat bawah untuk nilai mean dan standart deviasi variable impresi memiliki nilai yang menyatakan setuju dan nilai standart deviasi memiliki nilai yang mampu untuk mewakili seluruh populasi

\section{Analisa Regresi Linear Berganda}

Tabel 3. Analisa Regresi Linear Berganda

\begin{tabular}{clc}
\hline $\mathbf{R}$ & $\boldsymbol{R}^{\mathbf{2}}$ & Adjusted $\boldsymbol{R}^{\mathbf{2}}$ \\
\hline $.616^{a}$ & .379 & .366 \\
\hline
\end{tabular}

Pada tabel 3 dapat terlihat bahwa variabel bebas berpengaruh terhadap variabel terikat sebesar 36,6\%, dan $63,4 \%$ dipengaruhi oleh faktor-faktor lain. Pada penelitian oleh Countryman \& Jang (2006) layout sebagai salah satu variabel penelitian yang dilakukan pada lobby hotel ternyata juga berpengaruh secara tidak signifikan terhadap impresi, sedangkan faktor yang berpengaruh adalah warna, style dan pencahayaan. Sedangkan pada penelitian Ryu \& Jang (2008) terdapat juga berkata demikian bahwa layout memiliki skor terendah dibandingkan faktor-faktor lain seperti pencahayaan, ambience dan facility aesthetic.

\section{Uji F}

Tabel 4. Uji F

\begin{tabular}{ccc}
\hline Model & F & Sig \\
\hline Regression & 28.714 & $.000^{b}$ \\
\hline
\end{tabular}

Berdasarkan tabel 4 nilai yang ditunjukkan bahwa variabel-variabel bebas pada penelitian ini berpengaruh secara simultan terhadap variabel $\mathrm{Y}$ (Impresi). 


\section{Uji T}

Tabel 5. Uji F

\begin{tabular}{l|c|c|c|c}
\hline \multicolumn{1}{c|}{ Model } & \multicolumn{2}{|c|}{ Unstandardized Coefficients } & T & Sig \\
\cline { 1 - 2 } & $\mathbf{B}$ & Std.error & & \\
\hline (constant) & 4.349 & .999 & 4.351 & .000 \\
\hline Ambience & .142 & .054 & 2.624 & .010 \\
\hline Layout & .096 & .060 & 1.592 & .114 \\
\hline Facility & .167 & .035 & 5.277 & .000 \\
Aesthetic & & & & \\
\hline
\end{tabular}

Pada hasil uji T di tabel 5 terlihat bahwa variabel facility aesthetic berpengaruh secara positif dan signifikan terhadap impresi konsumen pada kedai kopi kekinian. Sedangkan pada variabel ambience, faktor ambience berpengaruh secara positif dan signifikan terhadap impresi konsumen pada kedai kopi kekinian setelah faktor facility aesthetic. Sedangkan pada variabel layout terlihat bahwa variabel layout tidak berpengaruh secara pada variabel impresi pada kedai kopi kekinian.

Hasil penelitian mengatakan bahwa ambience berpengaruh secara positif dan signifikan terhadap impresi. Penelitian ini sejalan dengan penelitian oleh Ryu \& Jang (2008) dimana variabel pencahayaan sebagai bagian dari variabel ambience, pernyataan yang memiliki nilai mean terbesar adalah "pencahayaan pada kedai kopi menciptakan suasana yang nyaman'. Pada penelitian Countryman \& Jang (2006) mengatakan bahwa tren pencahayaan adalah pencahayaan yang natural yang didapatkan dari sinar matahari, hal tersebut sejalan dengan hasil penelitian penulis dimana faktor pencahayaan mendapatkan nilai terbesar dibandingkan faktor-faktor lainnya. Menurut Baker et al. (1994); Sharma \& Stafford (2000) yang dikutip oleh Countryman \& Jang (2006) pencahayaan yang lembut biasanya dikaitkan dengan lingkungan berkualitas lebih tinggi. Menurut Ryu \& Jang (2008) ini berhubungan dengan bagaimana bagi konsumen pencahayaan bisa mempengaruhi kenyamanan selama berada pada sebuah fasilitas. Hal ini menunjukkan bahwa pencahayaan dari variabel ambience dalam kedai kopi kekinian merupakan indikator yang dinilai penting, namun dengan adanya pencahayaan natural tersebut dapat menimbulkan kenaikan suhu/temperatur pada kedai kopi kekinian. Suhu merupakan faktor dalam ambience yang memiliki nilai mean terendah sehingga dapat disimpulkan bahwa konsumen kedai kopi kekinian lebih mementingkan pencahayaan yang baik daripada suhu yang nyaman. Sama seperti warna dapat mempengaruhi ambience secara keseluruhan pencahayaan juga dapat mempengaruhi dimensi lain, seperti estetika fasilitas dan suasana. Pencahayaan dapat berinteraksi secara selaras dengan warna untuk menciptakan sinergi dalam menciptakan suasana dan nilai estetika. Berikut beberapa contoh kedai kopi kekinian yang menggunakan sinar alami sebagai pencahayaan.

Berdasarkan hasil penelitian, terhadap hubungan yang positif dan signifikan pada facility aesthetic terhadap impresi konsumen, penelitian ini sejalan dengan penelitian Ryu \& Jang (2008) dan Countryman \& Jang (2006) yang dilakukan pada restoran dan lobby hotel. Pada penelitian yang dilakukan oleh Countryman \& Jang (2006) hasilnya adalah bahwa meskipun ada salah satu variabel yang dianggap tidak menarik, tetapi jika diaplikasikan dengan variabel lain dapat menjadi sesuatu yang unik dan dapat disukai. Jika dilihat dari nilai mean pada variabel facility aesthetic indikator warna mempunyai nilai mean yang paling tinggi. Warna-warna tertentu yang dikombinasikan dengan warna lain bisa diterima dan disukai (Countryman \& Jang, 2006). Pada variabel facility aesthetic 'warna yang hangat' sebagai indikator yang memiliki nilai mean terbesar dan yang kedua kenyamanan tempat duduk. Hal ini dapat berarti bahwa konsumen dalam kedai kopi mencari kedai kopi yang memiliki nuansa hangat dan nyaman mengingat berdasarkan hasil survey yang mayoritas responden yang yang memilih untuk minum di tempat memiliki tujuan untuk berkumpul bersama teman. Responden menjawab bahwa alasan responden berkunjung ke kedai kopi adalah untuk "cangkruk" "nongkrong" dan bahwa kedai kopi yang dikunjungi merupakan tempat yang "nyaman, bagus dan menarik".

Berdasarkan hasil perhitungan untuk variabel layout dapat ditarik kesimpulan bahwa hipotesis terhadap variabel layout 'Layout berpengaruh secara signifikan pada impresi konsumen' ditolak, variabel layout sendiri tidak dapat mempengaruhi impresi konsumen namun jika diikuti dengan facility aesthetic dan ambience dapat mempengaruhi impresi pada konsumen. Dari variabel layout, kapasitas duduk pada kedai kopi kekinian merupakan faktor dalam layout yang memiliki nilai mean paling rendah. Hal ini sejalan dengan hasil wawancara dari Tantoputro selaku pemilik salah satu gerai Lain Hati di Surabaya yang menyatakan bahwa lebih banyak konsumen yang memilih untuk memesan produknya via online ataupun takeaway sehingga dapat disimpulkan kapasitas tempat duduk pada kedai kopi bukan merupakan hal yang penting bagi sebagian besar konsumen kedai kopi kekinian. Berdasarkan hasil penelitian yang dilakukan oleh Countryman \& Jang (2006) ditemukan bahwa layout tidak sepenting yang diperkirakan pada impresi konsumen pada lobby hotel selain itu pada penelitian Ryu \& Jang (2008) dari faktor lingkungan fisik yang 
diteliti pada luxury restaurants, variabel lingkungan fisiknya, layout juga memiliki nilai terkecil meskipun pada penelitian tersebut variabel layout masih berpengaruh secara signifikan.

Dari hasil penelitian di atas, dapat dikatakan bahwa variabel pada penelitian ini yaitu ambience, layout dan facility aesthetic berpengaruh secara simultan terhadap impresi konsumen pada kedai kopi kekinian. Pernyataan tersebut dibuktikan melalui hasil uji F. Ketiga variabel tersebut berpengaruh sebesar $36.6 \%$ terhadap impresi, dilihat dari hasil pada uji koefisien determinasi, belum ada penelitian yang memberitahukan faktor-faktor apa saja yang dapat mempengaruhi impresi selain ambience, layout dan facility aesthetic, namun kekurangan tersebut bisa dilakukan pada penelitian berikutnya.

\section{SIMPULAN DAN SARAN}

Para pebisnis kedai kopi agar menekankan nilai estetika dan suasana pada lingkungan fisik kedai kopi, layout yang luas/tidak sempit bisa menjadi nilai tambahan untuk mendapat impresi yang lebih baik pada kedai kopi kekinian. Menciptakan lingkungan fisik pada kedai kopi kekinian dengan menciptakan suasana yang nyaman dan menekankan pada nilai estetika, contohnya pencahayaan yang baik dengan sinar matahari/pencahayaan natural, aroma yang menyenangkan (aroma kopi/pewangi ruangan), kombinasi warna yang dapat menciptakan suasana hangat (cenderung coklat/krem), dll.

\section{DAFTAR REFERENSI}

Alfirahmi, A. (2019). Fenomena kopi kekinian di era 4.0 ditinjau dari marketing 4.0 dan teori uses and effect. LUGAS Jurnal Komunikasi, 3(1), 24-32.

Arikunto, S. (2006). Prosedur penelitian suatu pendekatan praktik. Jakarta: Rineka Cipta.

Bitner, M. J. (1992). Servicescapes: The Impact of Physical Surroundings on Customers and Employees. Journal of Marketing, 56(2), 57-71

Blanchard, R. (2005). The digital challenge for libraries: Understanding the culture and technology of total information. IUniverse.

Crespo, C. J. (1998, March). Update on national data on asthma. Paper presented at the meeting of the National Asthma Education and Prevention Program, Leesburg, VA.

Erinda, A. \& Kumadji, S. (2016). Analisis faktorfaktor preferensi pelanggan dan pengaruhnya terhadap keputusan pembelian (Studi Terhadap
Pelanggan McDonald's di Indonesia dan Malaysia). Jurnal Administrasi Bisnis, 30(1), 87-95.

Cohen, \& Swerdlik. (2009). Psychological testing \& assessment: An introduction to tests \& measurement. United States of America: McGraw-Hill.

Country, C. C. \& Jang, S.C. (2006). The effects of atmospheric elements on customer impression: the case of hotel lobbies. International Journal of Contemporary Hospitality Management, 18(7), 534-545.

Durna, U., Dedeoglu, B. B., \& Balikçioglu, S. (2015). The role of servicescape and image perceptions of customers on behavioral intentions in the hotel industry. International Journal of Contemporary Hospitality Management, 27(7), 1728-1748.

Falkner, L. (2020). An exploratory study of generational coffee preferences.

Ferdinand, A. T (2006). Metode penelitian manajemen: pedoman penelitian untuk skripsi. Tesis dan Disertasi Ilmu Manajemen. Semarang: Universitas Diponegoro.

Ghozali, I. (2012.) Aplikasi Analisis Multivariate dengan Program IBM SPSS. Yogyakarta: Universitas Diponegoro

Gumiwang, R. \& Syafina, D. C. (2019, December 17). Pasar Bisnis Kedai Kopi di Indonesia Sudah Tembus Rp 4,8 triliun. Retrieved from https://tirto.id/pasar-bisnis-kedai-kopi-di-indonesia-sudah-tembus-rp48-triliun-enBQ

Hamilton, I. S. (2007). Dictionary of psychological testing: assessment and treatment. London; Philadelphia: Jessica Kingsley.

Jani, D. \& Han, H. (2014). Personality, satisfaction, image, ambience, and loyalty: Testing their relationships in the hotel industry. International Journal of Hospitality Management, 18(7), 534545.

Jogiyanto, \& Abdillah, W. (2009). Konsep dan Aplikasi PLS (Partial Least Square) untuk Penelitian Empiris. Yogyakarta: BPFE.

Khan, M. A. (2006). Consumer behaviour and advertising management. New Age International (P).

Kuncoro, M. (2003), Metode Riset untuk Bisnis \& Ekonomi, Bagaimana

Meneliti \& Menulis Tesis, Erlangga, Jakarta.

Kotler, P. (1973). Atmospherics as a marketing tool. Journal of Retailing, 49(4), 48-64.

Kotler, P. 1997. Manajemen Pemasaran Analisis, Perencanaan, Implementasi dan Kontrol. Jakarta: PT. Prehallindo.

Kopi di Indonesia, Sejarah Singkat Tentang Proses Penyebarannya di Negeri Ini. (2019, March 19). Retrieved from https://jurnalbumi.com/knol/ sejarah-kopi/ 
Kaçan, U. \& Erdoğan, H. H. (2017, June). A culinary tourism innovation: The fourth wave of coffee. Paper presented at 9th World Conference for Graduate Research in Tourism Hospitality and Leisure, Cartagena, Spain.

Liana, L. (2009). Penggunaan MRA dengan SPSS untuk menguji pengaruh variabel moderating terhadap hubungan antara variabel independen dan variabel dependen. Dinamik, 14(2).

Lin, I. Y., \& Mattila, A. S. (2010). Restaurant servicescape, service encounter, and perceived congruency on customers' emotions and satisfaction. Journal of hospitality marketing \& management, 19(8), 819-841.

Muhammad, A., \& Sungplee, S. (2015). Factors of Customer's Preference of Visiting Coffee Shop in South Korea. International Journal of Sciences: Basic and Applied Research, 24, 252-265.

Pindyck, R. S. \& Rubinfeld, D. L. (2009). Microeconomics. Upper Saddle River, N.J: Pearson/ Prentice Hall.

Prasetyo, B., \& Jannah, L. M. (2005). Metode penelitian kuantitatif: teori dan aplikasi. Jakarta. Raja Grafindo Persada.

Ryu, K. \& Jang, S. S. (2007). The effect of environmental perceptions on behavioral intentions through emotions: The case of upscale restaurants. Journal of Hospitality \& Tourism Research, 31(1), 56-72.

Santoso, S., \& Tjiptono, F. (2001). Riset Pemasaran: konsep dan aplikasi dengan SPSS. PT. Elex Media Komputindo, Jakarta.
Setiadi, N. J. (2003). Perilaku konsumen: Konsep dan implikasi untuk strategi dan penelitian pemasaran. Jakarta: Prenada Media

Sugiyono. (2013). Metode Penelitian Kuantitatif, Kualitatif dan R\&D. Bandung: Alfabeta.CV

Santoso, P. B., \& Ashari. (2005). Analisis statistik dengan microsoft excel dan SPSS. Yogyakarta: Andy Publisher.

Shahbandeh, M. (2019, February 14). Top coffee producing countries 2018. Retrieved from https://www.statista.com/statistics/277137/world -coffee-production-by-leading-countries/

Simamora, B. 2003. Panduan Riset Perilaku Konsumen, Penerbit PT. Gramedia Pustaka Utama, Jakarta.

Sularso, S. (2003). Buku Pelengkap Metode Penelitian Akuntansi Sebuah Pendekatan Replikasi. Edisi Revisi 2003/2004. Yogyakarta: BPFE Yogyakarta.

Tedeschi, J. T. (1984). Impression management theory and social psychological research. Acad. Press.

Toffin. (2020). 2020 Brewing In Indonesia: Insights for Successful Coffee Shop Business.

Wakefield, K. L., \& Blodgett, J. G. (1994). The Importance of Servicescapes in Leisure Service Settings. Journal of Services Marketing, 8(3), 66-76.

Widiati, S. (2020, June 30). The Emerging Business of Coffee Shops in Indonesia. Retrieved from https://nowjakarta.co.id/dining/culinary-talk/theemerging-business-of-coffee-shops-in-indonesia. 